\title{
WHATSAPP COMO AMBIENTE DE INTERAÇÃO SOCIAL E APRENDIZAGENS DURANTE O ENSINO REMOTO EMERGENCIAL
}

Lia Cristiane Lima Hallwass ${ }^{1}$

Valdirene Hessler Bredow ${ }^{2}$

\section{RESUMO}

O Ensino Remoto Emergencial (ERE) se mostrou uma possibilidade diante da pandemia causada pela COVID-19. Por outro lado, trouxe muitos desafios, em particular no que se refere à interação e aprendizagem de estudantes de cursos presenciais. Baseado na perspectiva histórico-cultural da aprendizagem e nos estudos sobre uso de tecnologias educacionais digitais, o objetivo deste estudo é analisar o uso do aplicativo WhatsApp como ambiente de interação social e de aprendizagens durante o ERE. Este estudo qualitativo e exploratório teve sua coleta de dados baseada no fichamento de conversas entre professores e estudantes de graduação, durante o primeiro semestre de 2020, as quais foram analisadas conforme categorias temáticas e conforme os objetivos da interação: gerais, tecnologias e aprendizagens. Seus resultados mostram, principalmente, que a praticidade, a acessibilidade, a familiaridade e a afinidade dos estudantes com o WhatsApp foram determinantes para a manutenção dos processos de aprendizagem durante o ERE, transformando $O$ aplicativo de ferramenta complementar em ferramenta altamente potente para dúvidas sobre conteúdos, sobre processos, sobre as próprias tecnologias e de interação social entre os pares, respaldando suas aprendizagens. Pode-se concluir que o uso de tecnologias não educacionais, como o WhatsApp, foi de

1 Doutoranda do Programa de Pós-Graduação em Educação. Universidade Federal de Pelotas (UFPel). ORCID: https://orcid.org/0000-0002-3380-8669. E-mail: liahallwass@gmail.com

2 Doutoranda do Programa de Pós-Graduação em Educação. Universidade Federal de Pelotas (UFPel). ORCID: https://orcid.org/0000-0001-9267-9003 E-mail: valhessler@gmail.com 
utilidade na educação não somente durante o ERE, mas também pôde contribuir ainda pelo seu potencial de aproximação entre os pares. O aplicativo de mensagens mostrou-se, por meio de seus canais, uma possibilidade acessível, de forma que a interação social e os processos de aprendizagem fossem sustentados nesse momento de incerteza.

Palavras-chave: Ensino Remoto Emergencial. Tecnologias Educacionais Digitais. Aprendizagem.

\section{WHATSAPP AS AN ENVIRONMENT FOR SOCIAL INTERACTION AND LEARNING DURING EMERGENCY REMOTE TEACHING}

\section{ABSTRACT}

The emergency remote education (ERE) proved to be a possibility in the face of the pandemic caused by COVID-19. On the other hand, it brought many challenges, particularly with regard to the interaction and learning of students in classroom courses. Based on the historical-cultural perspective of learning and studies on the use of educational technologies, the objective of this study is to analyze the use of the WhatsApp application as an environment for social interaction and learning during the ERE. This qualitative, exploratory study had its data collection based on the record of conversations between professors and undergraduate students, during the first semester of 2020, which were analyzed according to thematic categories according to the objectives of the interaction: general, technologies and learning. Its results show, mainly, that the practicality, accessibility, familiarity and affinity of students with WhatsApp were decisive for the maintenance of learning processes during $E R E$, transforming the application as a complementary tool into a highly powerful tool for questions about content, on processes, on the technologies themselves and on social interaction between peers, supporting their learning. It can be concluded that the use of non-educational technologies, such as WhatsApp, was of use in education not only during the ERE, but also could contribute to its 
potential for bringing peers closer together. The messaging application proved, through its channels, an accessible possibility so that social interaction and learning processes were sustained in this moment of uncertainty.

Keywords: Emergency Remote Teaching. Digital Educational Technologies. Learning.

\section{WHATSAPP COMO ENTORNO DE INTERACCIÓN SOCIAL Y APRENDIZAJE DURANTE LA ENSEÑANZA REMOTA DE EMERGENCIA}

\section{RESUMEN}

La Educación Remota de Emergencia (ERE) demostró ser una posibilidad ante la pandemia causada por COVID-19. Por otro lado, trajo muchos desafíos, particularmente con respecto a la interacción y el aprendizaje de los estudiantes en los cursos en el aula. Basado en la perspectiva histórico-cultural del aprendizaje y los estudios sobre el uso de tecnologías educativas, el objetivo de este estudio es analizar el uso de la aplicación WhatsApp como un entorno para la interacción social y el aprendizaje durante el ERE. Este estudio exploratorio cualitativo tuvo su recopilación de datos basada en el registro de conversaciones entre profesores y estudiantes de pregrado, durante el primer semestre de 2020, que se analizaron según categorías temáticas de acuerdo con los objetivos de la interacción: general, tecnologías y aprendizaje. Sus resultados muestran, principalmente, que la practicidad, accesibilidad, familiaridad y afinidad de los estudiantes con WhatsApp fueron decisivos para el mantenimiento de los procesos de aprendizaje durante el ERE, transformando la aplicación como una herramienta complementaria en una herramienta muy poderosa para preguntas sobre el contenido, sobre procesos, sobre las tecnologías mismas y sobre la interacción social entre pares, apoyando su aprendizaje. Se puede concluir que el uso de tecnologías no educativas, como WhatsApp, fue de utilidad en la educación no solo durante el ERE, sino que también podría contribuir a su potencial para acercar a sus 
pares. La aplicación de mensajería demostró, a través de sus canales, una posibilidad accesible para que la interacción social y los procesos de aprendizaje se mantuvieran en este momento de incertidumbre.

Palabras clave: Educación Remota de Emergencia. Tecnologías Educativas Digitales. Aprendizaje.

\section{INTRODUÇÃO}

A COVID-19 exibiu todas as características de uma pandemia de classe, gênero e raça (ANTUNES, 2020), ameaçando a vida humana ao redor do globo (ARRUDA, 2020), das nações mais às menos desenvolvidas. Apesar dos esforços de mitigação do "todos estamos juntos" (idem, p. 12), cada nação lutou a seu modo contra os efeitos causados em suas áreas social, econômica, política etc., todas impactadas, bem como a área educacional.

No cenário brasileiro, a educação foi surpreendida pela urgência de reorganizar-se remotamente para a manutenção do ano letivo de 2020, perante os efeitos da pandemia causada pela COVID19. A partir de março desse ano, portarias de caráter provisório passaram a permitir a substituição de aulas presenciais por aulas em meios digitais, criando o que se convencionou chamar de Ensino Remoto Emergencial (ERE). Em junho, o Ministério da Educação estendeu a permissão até o final do ano (BRASIL, 2020). Essa reorganização se mostrou, portanto, como a melhor possibilidade educacional para a situação.

Contudo, as portarias tratavam da manutenção do ano letivo; não da aprendizagem. O ERE, além de acentuar desigualdades (ANTUNES, 2020; ANUP, 2020; ARRUDA, 2020), constituiu-se em um grande desafio para estudantes de cursos presenciais, que se viram, sem aviso prévio, migrando do modelo presencial para o remoto. Sem conhecimentos sobre tecnologias educacionais digitais (BELLONI, 1999; PAIS, 2005; LÉVY, 2007; BEHAR, 2020), sem tempo suficiente e sem suporte adequado, essa modalidade de ensino expôs estudantes a uma necessidade de encontrarem suas próprias formas de interação social e de aprendizagem (VYGOTSKY, 1984, 1995, 2000). 
Baseado na perspectiva histórico-cultural da aprendizagem e nos estudos sobre uso de tecnologias educacionais digitais, o objetivo deste trabalho é analisar o uso do aplicativo WhatsApp como ambiente de interação social e aprendizagens durante $O$ ERE praticado em 2020, a partir do fichamento de conversas entre estudantes e professores de graduação de uma faculdade privada no município de Porto Alegre/RS.

Este estudo qualitativo e exploratório foi realizado ao longo do primeiro semestre de 2020, o qual teve como base para a coleta de dados o fichamento de conversas entre estudantes e professores via grupo de WhatsApp. As conversas foram analisadas mediante análise temática, a partir de categorias consideradas relevantes para o estudo: interações gerais, interações sobre tecnologias e interações sobre aprendizagens.

\section{RELAÇÕES ENTRE INTERAÇÃO SOCIAL E APRENDIZAGENS E TECNOLOGIAS EDUCACIONAIS DIGITAIS}

Segundo a perspectiva histórico-cultural, os sujeitos são construídos a partir de suas relações sociais. Eles adquirem consciência em meio à convivência com seus pares, graças aos estímulos sociais recebidos (VYGOTSKY, 1984). Para Vygotsky, é o meio social que permite ao indivíduo atingir o ápice de seu desenvolvimento mental (VYGOTSKY, 1984; 1995; 2000). Em outras palavras, as relações sociais são tanto causas quanto resultados da aprendizagem (VYGOTSKY, 1984; 1995; 2000), pois são por meio delas que os indivíduos aprendem, constituem-se e se desenvolvem como seres humanos, apoiando-se nos pares e nas relações que têm com eles no decorrer da vida e no processo de aprendizagem contínua.

A interação social permite internalização de conhecimentos, experiências e entendimento sobre os próprios processos cognitivos (VYGOTSKY, 2000), os quais são as bases para a aprendizagem e, logo, para o desenvolvimento humano (HALLWASS, 2017; 2020). Essa internalização é um processo que ocorre da esfera social para a individual, graças à intervenção (mediação) de outro indivíduo que o 
respalda nesse processo (VYGOTSKY, 2000). A mediação, em outros termos, é entendida como o apoio de um sujeito mais experiente na aprendizagem de alguém menos experiente sobre determinado conhecimento (VYGOTSKY, 1984).

Por isso, interação social e mediação estimulam a internalização dos processos de aprendizagem (VYGOTSKY, 1995). Essa lógica de interação e aprendizagem acompanha o sujeito ao longo de toda a sua vida (MORETTI, 2009) e entendê-la pode oferecer subsídios para qualificar os processos individuais de aprendizagem, revelando novas formas interativas de construir, descontruir, reconstruir o conhecimento e propiciar uma nova qualidade da ação do sujeito frente às aprendizagens (HALLWASS, 2020). O processo de mediação docente se dá pelo comportamento do professor como facilitador, incentivador ou motivador da aprendizagem e desenvolvimento, apresentando disposição entre o aprendiz e sua aprendizagem, colaborando ativamente para que ele alcance seus objetivos (MASETTO, 2013).

As tecnologias entram nesse contexto como meios de facilitar aos indivíduos o acesso à educação (LOBO NETO, 2018). O computador, a internet, entre outros elementos do ciberespaço atendem às necessidades de interação entre os indivíduos (LÉVY, 2007), o que dá sentido radical às tecnologias e justificam sua penetrabilidade em diferentes realidades de informação, conhecimento e educação (LOBO NETO, 2008; HALLWASS, 2017). Elas vêm causando transformações significativas em diversos setores da vida social, inclusive revolucionando a educação (PAIS, 2005).

As tecnologias têm papel expressivo e potencializador na educação. Quando inseridas a partir de uma prática docente integrada com os objetivos e as metodologias de ensino (BREDOW, 2017; BREDOW; ZAMPERETTI, 2018), configuram-se importantes fontes de auxílio na construção do conhecimento. O destaque no método de aprendizagem através das tecnologias digitais e da mediação pedagógica faz com que o professor, ou outros sujeitos mais experientes, permita a participação dos estudantes no desenvolvimento de suas habilidades e valores próprios, admitindo também uma nova postura perante a seus pares (BREDOW, 2017). 
A interação social é suplementada pela midiatização tecnológica. Apesar do valor das metodologias tradicionais (presenciais), as tecnologias permitem superar ausência ou escassez de presença física (HALLWASS, 2019) e renovar os modos de interação entre os indivíduos (PAIS, 2005; UNESCO, 2013). Mais do que isso, elas redimensionam a construção e a socialização do conhecimento (LÉVY, 2007), processos de aprendizagem, de desenvolvimento humano e de educação formal (HALLWASS, 2017).

Nesse sentido, não é extremado dizer que cada vez mais as atualizações tecnológicas promovem mudanças na seara educacional. Isso é bem ilustrado quando se estuda as diferentes fases da educação a distância (EaD) (BELLONI, 1999). As tecnologias, dessa forma, não somente dão forma à EaD (HALLWASS, 2019) como também servem para situações emergenciais como a pandemia causada pela COVID-19.

Não foram poucas as iniciativas e as pesquisas que discutiram os impactos da pandemia na educação, entre os quais se inclui o ERE (ANUP, 2020; ARRUDA, 2020; BEHAR, 2020; COSTA et al., 2020; GARCIA et al., 2020; MOREIRA, HENRIQUES; BARROS, 2020). Todas pressupunham que essa modalidade de ensino remota não é sinônimo de EaD (BEHAR, 2020). No entanto, são suas tecnologias que estão permitindo a manutenção desse ensino em instituições educacionais nesse momento.

Dessa forma, dentre os momentos nos quais o ERE poderia ser necessário, a atual fase digital parece a mais adequada. Seus recursos e interatividades (HALWASS, 2019) reforçam as premissas de flexibilidade espaço-temporal da educação baseada em tecnologias digitais (idem). Porém, tecnologias educacionais digitais são comuns a estudantes a distância. Para eles, ambientes virtuais de aprendizagem são projeções digitais da instituição de ensino (HALLWASS, 2020); aulas on-line e videoaulas são aulas como qualquer outra. Estudantes presenciais, por vezes, têm relação limitada com tecnologias. Logo, é importante reforçar é que a educação presencial não é baseada em tecnologias (PAIS, 2005; BEHAR, 2020).

Aqui se tem o impasse: sem aviso prévio, estudantes presenciais migraram de um modelo conhecido (presencial) para 
outro inédito (ERE) (ARRUDA, 2020; BRASIL, 2020), primando pela manutenção do ano letivo, mas não pela aprendizagem. Além do desconhecimento sobre tecnologias educacionais digitais (LÉVY, 2007; BELLONI, 1999; PAIS, 2005; BEHAR, 2020; MOREIRA, HENRIQUES; BARROS, 2020), a situação não ofereceu tempo suficiente ou suporte adequado para a adaptação. Com efeito, estudantes foram expostos a uma necessidade de encontrarem suas próprias formas de interação social e de aprendizagem mediante tecnologias que não lhe são familiares.

Para vencer tal impasse, evocam-se as diretrizes para aprendizagem móvel da Unesco (2013). Elas discutem a ação dos gadgets na necessidade represada de aprender por meio das tecnologias, no contexto tecnológico atual em que os telefones celulares, por exemplo, possuem funções inteligentes e muito bem substituem computadores. Essas diretrizes tornam-se úteis para o $E R E$, permitindo a criação de uma rede social de aprendizagem em aplicativos de conversa, como o WhatsApp, crivada por presenças sociais que auxiliam a superar o distanciamento educacional causado pela pandemia (BEHAR, 2020). Além dessas facilidades, utilizá-los não empreende nenhum conhecimento novo, pois as facilidades trazidas pelos gadgets e seus aplicativos já fazem parte da vida cotidiana diferentemente das tecnologias educacionais digitais, as quais ainda não restam conhecidos por alunos de quaisquer modalidades de ensino.

\section{PROCESSO METODOLÓGICO}

Este é um estudo de cunho qualitativo e exploratório (GIL, 2007), que objetivou analisar o uso do aplicativo WhatsApp como ambiente de interação social e de aprendizagens durante o ERE. O estudo foi realizado ao longo do primeiro semestre de 2020, período em que portarias ministeriais permitiram o ensino por meios digitais devido à pandemia causada pela COVID-19 (BRASIL, 2020).

A base da coleta de dados foi o fichamento de conversas entre estudantes e professores (VERGARA, 2007; GIL, 2007), via grupo de WhatsApp. Importante registrar que, tão logo o Ministério da Educação permitiu o $\mathrm{ERE}$, dentre as primeiras iniciativas da 
coordenação do curso esteve a criação de grupos de WhatsApp por semestre (cada semestre do curso tinha um grupo), dos quais participavam a coordenação, os estudantes e os professores. Essa iniciativa foi usada como forma de manter a interação entre todos durante o período por meio do acompanhamento das atividades e dúvidas.

Os sujeitos pertencem a um curso de graduação tecnológica de uma faculdade privada no município de Porto Alegre/RS. Foram sujeitos $^{3}$ deste estudo nove estudantes do segundo semestre do curso tecnólogo e os cinco professores responsáveis pelas disciplinas desse mesmo semestre. Esse grupo foi escolhido intencionalmente (VERGARA, 2007), por algumas razões a saber: a quantidade de estudantes envolvidos e a intensa utilização do aplicativo como apoio às interações e aprendizagens.

As conversas foram analisadas mediante análise temática, buscando aspectos essenciais para o estudo (VERGARA, 2007), cuja organização das categorias se deu em função dos objetivos da interação, contemplando: interações gerais, interações sobre tecnologias e interações sobre aprendizagens.

\section{RESULTADOS DO ESTUDO}

Esta seção dedica-se a analisar o uso do aplicativo WhatsApp como ambiente de interação social e de aprendizagens durante o ERE praticado no primeiro semestre de 2020. Considerando o grande volume de mensagens ao longo do estudo, a seguir constam as conversas ${ }^{4}$ mais ilustrativas do uso do aplicativo, cada qual representando as categorias de análise previstas. Cabe dizer que algumas dessas conversas foram indicadas pelos sujeitos quando questionados sobre quanto o WhatsApp os auxiliou nas interações sociais e aprendizagens.

\footnotetext{
${ }^{3}$ As identidades dos sujeitos foram preservadas. Para apresentação dos resultados, cada um recebeu aleatoriamente um número de referência pelo qual serão mencionados.

${ }^{4}$ As conversas apresentadas focaram-se em aspectos essencialmente relevantes para o estudo. Foram suprimidos os muitos emojis utilizados e assuntos aleatórios, pois em conversas de WhatsApp é comum que se discuta muitos assuntos simultaneamente. Erros de português ou gramática, constam corrigidos.
} 
Em relação às interações gerais, os alunos discutiam sobre assuntos variados, desde questões cotidianas, de suas famílias, de suas dificuldades, de suas ocupações até relacionadas às expectativas em relação à própria pandemia e suas implicações.

Segue trecho de uma conversa:

Estudante 2: Professores, meu computador estragou.

O cara [responsável técnico] disse que não sabe se tem conserto. Não tenho como estudar.

Professor 3: Oi. Tu não tens como conseguir com alguém?

Estudante 7: Amiga, e agora?

Estudante 2: Eu posso ir à faculdade, professora? Está funcionando?

Professor 5: Não, amore, está fechada!

Estudante 9: Usa o celular, tu consegues assistir às aulas.

Estudante 2: Sim, mas não posso fazer os trabalhos.

Estudante 3: Eu só tenho o celular.

Estudante 2: E os trabalhos?

Professor 5: Faz assim, foca em não perder as aulas agora.

Tu tens alguma previsão de retorno da máquina?

Uma coisa de cada vez. Agora as aulas...

Depois nós [professores] te ajudamos com os trabalhos. Pode ser?

Estudante 2: O.k.! Assim que tiver notícias do [computador] doente eu aviso. Obrigada, amigos.

Professor 5: Não te preocupa.

Estudante 2: Eu vou tentar. Mas não quero desistir.

Professor 5: Não vai!

(Algumas semanas depois)

Estudante 2: Colegas, novidade! Meu computador voltou. Não está funcionando bem, não carrega direito, mas funciona.

Professor 5: Tu ainda consegues usá-lo?

Estudante 2: Mais ou menos, tem todo um jeito para poder carregar. 
Mas vou levando!

Professor 5: Então começa a dar uma olhada nos materiais e não deixa acumular muitas atividades.

Estudante 2: Nem sei por onde começar.

Professor 5: Vais ter que começar por algum lugar, né? Escolhe uma disciplina e vê as atividades. Vamos te ajudar! Vais ter que correr só.

Escolhe uma disciplina, vê as atividades, faz e, depois, fala com o professor da disciplina e combina a entrega. Outro dia faz a mesma coisa com outra disciplina.

Corre lá!

Estudante 2: Professora 5, obrigada por ajudar. E se eu não conseguir, o que acontece?

Professor 5: Primeiro, tu vais ter que tentar. Só assim vais saber.

Não pensa coisa ruim, vai lá e tenta.

Estudante 2: Entendi. Pode deixar!

A partir da conversa que retrata a forma como as interações gerais se deram por meio do aplicativo de mensagens WhatsApp, é possível perceber quanto 0 meio estimulou $o$ processo de aprendizagem para o aluno que relatava um problema particular (VYGOTSKY, 1984), fortalecendo então a importância da interação social e a mediação para estimulação e internalização como fortalecedora do processo de aprendizagem (VYGOTSKY, 1984; 1995; 2000; MORETTI, 2009; MASETTO, 2013). Como o meio era novo para todos, eles estavam se ambientando, e essas interações eram forma de manter a convivência com os pares (VYGOTSKY, 2000; HALLWASS, 2017, 2019).

Atualmente, a educação se encontra diante do desafio de construir um espaço de mediação e interação entre alunos, professores e o mundo tecnológico digital (BELLONI, 1999; LÉVY, 2007; HALLWASS, 2017; 2020). Mesmo que para alguns o processo seja lento e mais ímprobo, a sociedade contemporânea demanda que a educação agregue tecnologias ao ensino (PAIS, 2005; UNESCO, 2013; HALLWASS, 2017; LOBO NETO, 2018; BREDOW; ZAMPERETI, 2018), posicionando-se como mediadora do conhecimento (LÉVY, 
2007; HALLWASS, 2020), levando seus alunos a se apropriarem dos conhecimentos em uma interação permitida por meio da comunicação digital (BREDOW, 2017).

Outro ponto observado nas conversas foram as interações sobre tecnologias. Os estudantes discutiram muito sobre acessos, recursos e entregas de atividades, rematrícula, entre tantos, como problemas técnicos durante atividades síncronas.

Segue trecho de uma conversa:

Estudante 3: Oi, professora, tô bem perdido.

Professor 5: Oi. Com o quê, querido?

Estudante 3: Eu não consegui participar da aula na última semana, agora é tudo $\mathrm{EaD}$ e não estou entendendo como que faz para assistir às aulas. Eu posso assistir na faculdade?

Professor 5: Não, agora não vai dar.

Agora as aulas vão ser on-line, por causa do Coronavírus.

Estudante 3: Todo o ano?

Professor 5: Ainda não sabemos, mas neste semestre, pelo jeito, vai.

Estudante 3: E como vão ser as aulas e os trabalhos?

Professor 5: Tudo on-line. Daí tu só cuida os horários.

Estudante 3: A gente não vai ter mais aula?

Professor 5: Presencialmente não vai dar. Saiu uma portaria e vamos fazer tudo on-line, pela nossa segurança. Ainda não temos datas, mas não te preocupa.

Estudante 3: É que nunca estudei EaD.

Professor 5: Não é bem EaD. É igual às nossas aulas, só que ao invés de ir à faculdade tu vais acessar o link. Já entraste no Moodle?

Estudante 3: Então, professora, eu não sei direito onde tem que acessar.

Vergonha de ficar conversando ali no grupo.

Professor 5: Sem problemas.

Tudo é novo para todos!

No portal do aluno, tu sabes entrar? 
Estudante 3: Sim, para ver as notas.

Professor 5: Pois bem, por lá tu vais entrar no ambiente Moodle e vai poder assistir às aulas, fazer as atividades e tudo o mais.

Vais acessar com teu login: número da matrícula e senha.

Estudante 3: Sim, sim, o acesso eu fiz normalmente.

Professor 5: (foto) no menu à esquerda, vais ver as opções. Clica no link Moodle e vais entrar no ambiente onde tem as disciplinas e tudo que te falei.

Estudante 3: Sim, esse acesso eu não tinha.

Professor 5: Tinhas, só não tinhas visto.

(Foto) quando estiveres no Moodle, vais ver a lista de disciplinas em que te matriculaste.

(Foto) isso aqui e o espaço de uma disciplina.

(Vídeos) agora te fiz uns tutoriais caseiros. Dá uma olhada nele, porque eu fui clicando e comentando o que cada um deles faz.

Tu vais ver que o ambiente está organizado, e todos são iguais. Então, depois que entenderes um, tu vais ver que tudo está organizado nas mesmas ordens.

(Minutos depois)

Estudante 3: Professora, agora sim. Ah, é bem fácil!

Só não entendi onde eu entro na aula.

Professor 5: Viste como é fácil?

Sobre as aulas, num dos vídeos eu cliquei num link que dizia aula on-line e tem a data do lado.

Se tu clicares em alguma aula da semana passada, vais poder ver a gravação. Se clicares nas das semanas seguintes, não vai entrar, porque o horário ainda não chegou. Elas abrem no horário marcado da aula.

Estudante 3: Acho que não vi essa parte. Vou ver de novo.

Professor 5: Tu queres que te reforce os dias das aulas? Estudante 3: Não, professora, não precisa. Obrigado 
mesmo. Já vi que diz no grupo. Depois eu entro ali e pego.

Eu já andava preocupado.

Professor 5: O.k., se tiveres dúvidas, tens que nos chamar.

Ah, no dia da aula on-line, quando tu entrares, vê se vai liberar tua câmera, fone, microfone. Vai olhando e aceitando ou não. É que nem uma sala de bate-papo. Que achaste? Tudo certo?

Estudante 3: Supercerto!

Professor 5: Então, vamos falando. Qualquer coisa chama!

Estudante 3: Pode deixar comigo, professora!

Nesse contexto de maior necessidade interativa pelos meios digitais, o objetivo é facilitar para estudantes e professores o acesso à educação (LOBO NETO, 2008). A educação precisa da mediação que se dá na interação social, pois ela é a propulsora da construção do conhecimento (BREDOW, 2017; HALLWASS, 2017). Nisso, encontrase o uso das novas possibilidades de aprendizagem por meio das tecnologias digitais, facilitando o aprendizado, tornando-o dinâmico e interessante.

As interações tecnológicas se dão pelos elementos disponibilizados pelo ciberespaço, computador, internet, ambientes virtuais, entre outros meios (LÉVY, 2007; HALLWASS, 2017). Assim, as tecnologias digitais condicionam mudanças à medida que se criem condições para que elas ocorram desencadeadas pela transmissão de informações (BELLONI, 1999; PAIS, 2005; LÉVY, 2007; BREDOW; ZAMPERETTI, 2018), seja através da forma física ou, como no caso aqui analisado, digital (LÉVY, 1999; 2007), justificadas pela penetrabilidade do meio digital nas realidades de informação, conhecimento e educação (LOBO NETO, 2018; HALLWASS, 2017).

Durante todo o período, surgiram interações relacionadas às aprendizagens, em muito relacionadas às avaliações. $O$ aplicativo ajudou estudantes a entenderem e a checarem seus entendimentos e aprendizagens e também sugerindo discussões previas sobre avaliações. A particularidade dessas interações é que a maioria delas 
se fazia em ambiente privado, não nos grupos. A principal razão detectada para o comportamento era o medo da exposição perante o grupo.

Segue trecho de uma conversa:

Estudante 4: Professora 5, a senhora pode falar?

Professor 5: Oi. Posso! Tudo bem contigo?

Estudante 4: Acho que sim. Não sei. Eu acho que não entendi nada sobre o trabalho da matriz BCG.

Professor 5: Vamos começar do começo. Já assististes aos vídeos que fiz para vocês? Tu não estavas na aula on-line. Tu já assististe à gravação? Eu expliquei bem a atividade.

Estudante 4: Sim [assisti aos vídeos] e não [à gravação].

Professor 5: Tu já leste o material?

O relatório modelo para a atividade?

Estudante 4: Sim, esses já vi.

O problema é que acho que entendi a tarefa, eu acho que eu não entendi é o que é a matriz BCG. Na situação de aplicar à área de pessoas, a ideia seria eu classificar as pessoas conforme que critérios?

Se a classificação não for boa, e todo mundo for abacaxi, eu tenho que demitir tudo.

Eu não entendo, depois de classificar, o que eu faço com as pessoas.

Professor 5: Estás em um dilema ético?!? Estás brincando.

Não, a atividade não é para te levar a resultados tão drásticos.

Tu lembras com base em que critérios os produtos são analisados na BCG?

Estudante 4: Não sei. Se a senhora puder me lembrar, agradeço.

Professor 5: Participação relativa e crescimento no mercado.

Isso significa que um produto é bom quando tem uma boa participação no 
mercado e ainda tem possibilidade de crescer mais.

Estudante 4: E quando eu uso para pessoas?

Professor 5: Daí tu vais imaginar que os produtos são pessoas, que o mercado é a tua empresa. E vais imaginar como essas pessoas contribuem para a tua empresa e ainda podem crescer dentro dela. A ideia é tu entenderes que não adianta tu teres uma pessoa que não contribuiu na tua empresa, mas também não adianta tu ter uma pessoa que contribui muito, mas a tua empresa não permita que ela cresça. De uma forma ou de outra, terás um abacaxi.

Estudante 4: Professora, mas e se todo mundo for abacaxi, eu vou ter que demitir todo mundo?

Professor 5: A ideia não é demitir, amor. A ideia é tu identificares quem é quem, exatamente para não deixar que ninguém vire um abacaxi na tua empresa.

(Várias mensagens e áudios sobre detalhes da matriz)

Estudante 4: Professora, se eu fizer meu trabalho, a senhora olha antes de eu entregar lá no Moodle?

Professor 5: Olho, claro!

Estudante 4: trabalho encaminhado em Word.

(Uma hora depois)

Professor 5: retorno devolvido em Word.

Teu trabalho está ficando muito bom. O grupo de pessoas que escolheste é bom, grande. Fiz muitos comentários no teu texto. Falta a conclusão do teu relatório. Tens que comentar sobre todos, o.k.?

(Minutos depois)

Estudante 4: Ah, professora, agora, sim. Entendi!

Achei ótima! Eu acho que ela serve em tudo! Eu vou poder usar essa matriz numa empresa também?

Professor 5: Agora que entendeste, vais poder em qualquer portfólio. Muda os critérios de 
comparação e usa.

Essa matriz é uma das coisas mais legais da ADM.

Estudante 4: Tá bom!

Vou acertar essas coisas e postar no Moodle.

Obrigada por hoje, profe!

Nesse ponto observamos que estimular a aprendizagem através dos espaços virtuais pode ser uma ferramenta interessante para estimular os estudantes em relação às suas aprendizagens (BELLONI, 1999; VYGOTSKY, 1984; 2000; UNESCO, 2013) HALLWASS, 2019), pois dentro do conteúdo programático são trabalhadas teorias de diferentes áreas e nem todos os alunos as dominam igualmente (BREDOW, 2017), principalmente, em que pese ser este um momento de desafio de aprendizagens, por meio do ERE, aliando novas ferramentas que permitam a interação social e educacional para alunos e professores (ANUP, 2020; ARRUDA, 2020; BEHAR, 2020; COSTA et al, 2020; GARCIA et al, 2020; MOREIRA, HENRIQUES; BARROS, 2020).

Os resultados deste estudo mostram, principalmente, que a praticidade, a acessibilidade, a familiaridade e a afinidade dos estudantes com o WhatsApp foram determinantes para a manutenção dos processos de interação social e de aprendizagem durante O ERE (BREDOW, 2017; HALLWASS, 2017; 2019), transformando o aplicativo em ferramenta complementar e altamente potente para dúvidas sobre conteúdos, sobre processos, sobre as próprias tecnologias e de interação social entre os pares, respaldando tanto estudantes quanto professores, inclusive pela facilidade na troca de elementos visuais que davam apoio ao conhecimento que estava sendo discutido.

Em muitas situações, ele contribuiu fortemente para $O$ entendimento dos estudantes sobre o ERE (ANUP, 2020; ARRUDA, 2020; BEHAR, 2020; COSTA et al, 2020; GARCIA et al., 2020; MOREIRA; HENRIQUES; BARROS, 2020), sobre a manutenção do ano letivo (BRASIL, 2020) e de suas aprendizagens durante 2020. Outrossim, o WhatsApp foi uma fonte de apoio e manutenção da proximidade entre os pares, pois dada a escassez de tempo para adaptações, era 
através deles que todos se ajudavam num processo de mediação não somente voltada para suas aprendizagens (VYGOTSKY, 1984; 1995; 2000), mas sobre os acontecimentos relacionados à pandemia e ao momento de vida que todos estavam vivendo.

Considerando que os estudantes não têm conhecimento sobre tecnologias educacionais digitais (LÉVY, 2007; BELLONI, 1999; PAIS, 2005; BEHAR, 2020; MOREIRA; HENRIQUES; BARROS, 2020), ou especificamente sobre o funcionamento dos ambientes virtuais de aprendizagem (BREDOW, 2017; HALLWASS, 2020), a utilização do WhatsApp contribuiu inclusive para a redução do estresse de professores e estudantes sobre o funcionamento do ERE (BEHAR, 2020; BRASIL, 2020). Destaca-se que o aplicativo serviu como um complemento importante também para professores, cuja utilização não é objeto de pesquisa deste trabalho, mas que igualmente tiveram suporte a dúvidas sobre tecnologias. Além disso, o aplicativo de mensagens contribuiu ainda no respaldo aos professores para construírem parcerias de trabalho durante esse período.

\section{CONSIDERACÕES FINAIS}

Pode-se concluir que o uso de tecnologias digitais não educacionais, como o aplicativo WhatsApp, pode ser de utilidade na educação convencional não somente durante o ERE, mas para o ensino presencial também, pela praticidade e grande alcance que ele tem. O WhatsApp mostrou-se, por meio de seus canais, uma possibilidade acessível, de forma que a interação social e os processos de aprendizagem fossem sustentados nesse momento de incerteza.

As tecnologias digitais alteraram as formas de comunicação e interação da sociedade contemporânea, sendo possível ampliar e desdobrar a conexão entre o mundo real e o virtual. Em momentos de incerteza, como o causado pela pandemia, tornou-se mister a utilização dessas ferramentas digitais. Porém, deve-se entender que o uso de tecnologias digitais na educação e os estudos referentes a esse uso são aplicáveis a qualquer instância e nível educacional.

Assim, é preciso também entender que as relações educacionais acabaram sendo marcadas pela possibilidade de ligação 
entre pessoas de diferentes espaços geográficos, mas que por meio da comunicação digital e utilização de dispositivos móveis foi possível estabelecer novas e diferentes formas de ligação e troca de informações.

O ERE trouxe ao campo educativo novidades e desafios que permitiram também novas formas de interação, principalmente entre professores e alunos, para além do espaço físico da sala de aula. Assim, as tecnologias digitais educacionais propiciaram novos suportes e ferramentas que, incorporados às práticas pedagógicas, auxiliam as atividades de alunos e mudam a dinâmica de trabalho dos professores.

O estudo demonstrou em seus resultados que o WhatsApp foi uma ferramenta prática, pois os estudantes tinham familiaridade com ele, o que propiciou uma maneira acessível de trabalho e também de mais acesso entre as relações comunicacionais para estudantes e docentes da instituição de ensino de Porto Alegre/RS.

Além disso, a comunicação intermediada por esse aplicativo foi determinante para a manutenção dos processos de interação, mediação e aprendizagem durante o ERE, transformando o WhatsApp em um dispositivo que, inicialmente, seria apenas um meio complementar, porém se mostrou altamente potente para sanar dúvidas sobre conteúdos, processos de acessos, sobre as próprias tecnologias e de interação social, corroborando para o trabalho/aprendizagem tanto de estudantes quanto de professores.

Conclui-se, assim, que a utilização do WhatsApp contribuiu inclusive para a redução do distanciamento que o ERE poderia ocasionar entre professores e estudantes, tornando-se mais um ambiente interativo, como o próprio ambiente virtual de aprendizagem tradicionalmente presente na educação, embora baseado em tecnologias digitais.

\section{REFERÊNCIAS}

ANTUNES, R. Coronavírus: o trabalho sob fogo cruzado. São Paulo: Boitempo, 2020. 
ANUP. Educação Pós-pandemia e a Urgência da Transformação

Digital. 2020. Disponível: https://anup.org.br/noticias/educacaopos-pandemia-e-a-urgencia-da-transformacao-digital/. Acesso: 31 maio 2020.

ARRUDA, E. P. Educação Remota Emergencial: elementos para políticas públicas na educação brasileiras em tempos de COVID-19. Em Rede, v. 7, n. 1, p. 257-275, 2020.

BEHAR, P. A. O Ensino Remoto Emergencial e a Educação a

Distância. Disponível: https://www.ufrgs.br/jornal/o-ensino-remotoemergencial-e-a-educacao-a-distancia/. Acesso: jul-2020.

BELLONI, M. L. Educação a Distância. São Paulo: Autores Associados, 1999.

BRASIL. Portaria MEC n. 544 de 16 de Junho de 2020. Dispõe sobre a substituição das aulas presenciais por aulas em meios digitais, enquanto durar a situação de pandemia do novo coronavírus - COVID-19, e revoga as Portarias MEC n 343, de 17 de março de 2020, n 345, de 19 de março de 2020, e $n^{\circ} 473$, de 12 de maio de 2020. Brasília, 2020.

\section{BREDOW, V. H. O Facebook nas Práticas Educativas}

Contemporâneas: interações de alunos e professores no Ensino Médio. 2017. 156f. Dissertação (Mestrado em Educação) - Programa de Pós-Graduação Educação, Faculdade de Educação - FaE, Universidade Federal de Pelotas, Pelotas, 2017.

BREDOW, V. H.; ZAMPERETTI, M. P. Facebook e Escola: novas interações entre professores e alunos. Momento-Diálogos em Educação, v. 27, n. 1, p. 245-265, 2018.

COSTA, R. et al. Ensino de Enfermagem em Tempos de COVID-19: Como se reinventar nesse contexto? Texto \& Contexto Enfermagem, v. 29, p. 1-3, 2020.

GARCIA, T. C. M. et al Ensino Remoto Emergencial: orientações para elaboração do plano de aula. Natal: SEDIS/UFRN, 2020.

GIL, A. C. Como Elaborar Projetos de Pesquisa. $4^{\circ}$ ed. São Paulo: Atlas, 2007 
HALLWASS, L. C. L. A Perspectiva Vygotskyana na Formação Docente Online: Observações na educação superior. Texto Livre, v. 13, p. 119, jan/abr, 2020.

HALLWASS, L. C. L. Para Além da Teoria - Interação Social e Atividades Práticas como Elementos Essenciais na Aprendizagem de Estudantes de Cursos Híbridos. In: Gabriela Rossetti Ferreira. (Org.).

Educação e Tecnologias: Experiências, Desafios e Perspectivas. 2. Ed. Ponta Grossa: Atena, 2019, v. 2, p. 160-176.

\section{HALLWASS, L. C. L. Programa de Qualificação de Trabalhos de}

Conclusão de Curso: ações focadas na qualidade dos trabalhos acadêmicos. In: $22^{\circ}$ Seminário de Educação, Tecnologia e Sociedade. Taquara. Atas... Taquara: Faculdades Integradas de Taquara, 2017.

LÉVY, Pierre. As Tecnologias da Inteligência: o futuro do pensamento na era da informática. Rio de Janeiro: 34, 2007.

LOBO NETO, F. J. da S. Educação: prática social. 2008. Disponível: http://floboneto.pro.br/_pdf/educacao/1.01\%20EDUCA\%C3\%87\%C3 \%830pr\%C3\%A1ticasocial.pdf. Acesso: 30 out. 2018.

MASETTO, M. T. Mediação Pedagógica e o Uso da Tecnologia. In. MORAN, J. M.; MASETTO, M. T.; BEHRENS, M. A. Novas Tecnologias e mediação pedagógica. 6. ed. Campinas: Papirus, 2013.

MOREIRA, J. A. M.; HENRIQUES, S.; BARROS, D. Transitando de um Ensino Remoto Emergencial para uma Educação Digital em Rede, em Tempos de Pandemia. Dialogia, n. 34, p. 1-19, jan/abr, 2020.

MORETTI, V. D. Contribuiç̧̃̃es da Psicologia Histórico-Cultural para Atividade docente. In: IX Encontro Nacional de Psicologia Escolar e Educacional (Abrapee). São Paulo. Anais [...] São Paulo: Universidade Presbiteriana Mackenzie, 2009.

PAIS, L. C. Educação Escolar e as Tecnologias da Informática. Belo Horizonte: Autêntica, 2005.

UNESCO. Policy Guidelines for Mobile Learning. 2013. Disponível em: http://unesdoc.unesco.org/images/0021/002196/219641e.pdf. Acesso: 31 maio 2020. 
VERGARA, S. C. Projetos e Relatórios de Pesquisa em

Administração. São Paulo: Atlas, 2007.

VYGOTSKY, L. S. A Construção do Pensamento e da Linguagem.

São Paulo: Martins Fontes, 2000.

VYGOTSKY, L. S. A Formação Social da Mente: o desenvolvimento dos processos psicológicos superiores. São Paulo: Martins Fontes, 1984.

VYGOTSKY, L. S. Teoria e Método em Psicologia. São Paulo:

Martins Fontes, 1995.

Submetido em: Agosto/ 2020.

Aceito em: Março/ 2021. 